\title{
Atividade Microbiana e Produção de Milho (Zea mays) E DE Brachiaria brizantha SOB DIFERENTES MÉTOdOS DE CONTROLE DE Plantas Daninhas ${ }^{1}$
}

\author{
Microbial Activity and Production of Corn (Zea mays) and Brachiaria brizantha Under \\ Different Methods of Weed Control
}

JAKELAITIS, A. ${ }^{2}$, SANTOS, J.B. ${ }^{3}$, VIVIAN, R. $^{3}$ e SILVA, A.A. ${ }^{4}$

\begin{abstract}
RESUMO - Avaliaram-se nesta pesquisa os efeitos dos herbicidas atrazine + nicosulfuron aplicados no consórcio entre milho a Brachiaria brizantha sobre a atividade microbiana do solo e a produtividade de ambas as espécies consorciadas. Os tratamentos constituíram-se do consórcio entre o milho e a forrageira $B$. brizantha, tratado com os herbicidas atrazine $\left(1.500 \mathrm{~g} \mathrm{ha}^{-1}\right)$ ou a mistura deste com nicosulfuron $\left(0,4 \mathrm{e} 32 \mathrm{~g} \mathrm{ha}^{-1}\right)$, e de duas testemunhas, representadas pelo consórcio capinado e sem capina. Os herbicidas foram aplicados 30 dias após a emergência (DAE) do milho. Utilizou-se o delineamento em blocos casualizados, com quatro repetições. Foram avaliados a respiração, a biomassa microbiana (BM) e o quociente metabólico $\left(\mathrm{qCO}_{2}\right)$ de amostras de solo coletadas aos sete dias após a aplicação dos herbicidas (DAA), no florescimento e em pré-colheita do milho. Amostras de solo não tratadas foram coletadas a campo e tratadas com herbicidas atrazine $\left(1.500 \mathrm{~g} \mathrm{ha}^{-1}\right)+$ nicosulfuron $(0,2,4,8$, 16 e $32 \mathrm{~g} \mathrm{ha}^{-1}$ ) em laboratório, onde se determinaram também a respiração, a BM e o qCO ${ }_{2}$. Em pré-colheita do milho, avaliaram-se as massas secas das plantas daninhas e da forrageira e o rendimento de grãos de milho. Observou-se que os métodos de controle não influenciaram a respiração, a $\mathrm{BM}$ e o $\mathrm{qCO}_{2}$ no solo nas três épocas avaliadas em campo e nas amostras de solo tratadas em laboratório. Todavia, em campo, verificou-se maior BM por ocasião do florescimento e maior $\mathrm{qCO}_{2}$ após a aplicação dos herbicidas, aos 7 DAA. Maior produção de massa seca de plantas daninhas foi observada nas parcelas não-capinadas e naquelas tratadas somente com atrazine. O rendimento forrageiro de $B$. brizantha foi superior no consórcio capinado, enquanto o rendimento de grãos de milho foi superior tanto no consórcio capinado quanto nas parcelas tratadas com nicosulfuron.
\end{abstract}

Palavras-chave: atrazine, biomassa microbiana, consórcio, nicosulfuron, plantio direto, quociente metabólico.

\begin{abstract}
This study aimed to evaluate the effects of atrazine + nicosulfuron on soil microbial activity and biomass production of corn and Brachiaria brizantha intercroping. The treatments were constituted of corn and $\boldsymbol{B}$. brizantha intercropping, treated with atrazine $\left(1,500 \mathrm{~g} \mathrm{ha}^{-1}\right)$, or with atrazine + nicosulfuron $\left(0,4\right.$ and $\left.32 \mathrm{~g} \mathrm{ha}^{-1}\right)$ and two controls represented by intercropping control with and without weeds. Herbicides were applied 30 days after corn emergence (DAE). The experiment was arranged in a randomized block design, with four replicates. Microbial biomass $(\mathrm{MB})$, respiration and metabolic quotient $\left(\mathrm{qCO}_{2}\right)$ obtained from soil samples seven days after herbicide application on corn flowerage and pre-harvesting were evaluated. No-treated soil samples were collected in field and treated with atrazine $\left(1,500 \mathrm{~g} \mathrm{ha}^{-1}\right)+$ nicosulfuron $(0,2$, 4, 8, 16 and $32 \mathrm{~g} \mathrm{ha}^{-1}$ ) under laboratory condition. Weed and B. brizantha dry matter and corn grain yield were evaluated at corn pre-harvesting. Methods of control did not influence respiration,
\end{abstract}

Recebido para publicação em 30.7.2006 e na forma revisada em 27.2.2007.

Professor do Departamento de Agronomia da Universidade Federal de Rondônia - UNIR, Av. Norte Sul, 7300, 78987-000 Rolim de Moura-RO, <ajakelaitis@unir.br>. ${ }^{3}$ Pós-graduando do Departamento de Fitotecnia da Universidade Federal de Viçosa - DFT/UFV, Av P. H. Rolfs, s/n, Campus da UFV, 36570-000 Viçosa-MG, <jbarbosasantos@yahoo.com.br>, <agrovivian@yahoo.com.br>; ${ }^{4}$ Professor Associado - DFT/UFV, <aasilva@ufv.br>. 


\begin{abstract}
$M B$ nor $q \mathrm{CO}_{2}$ but higher $M B$ in flowerage and higher $q \mathrm{CO}_{2}$ were observed after seven days of application. Higher weed dry matter production was observed in the control treated only with atrazine. Forage yield of $\mathrm{B}$. brizantha was superior in the control plots without weeds, while corn grain yield was superior both in the control plots without weeds and treated with nicosulfuron.
\end{abstract}

Keywords: atrazine, microbial biomass, intercrop, nicosulfuron, no-tillage, metabolic quotient.

\section{INTRODUÇÃO}

Recentemente, tem se observado crescente interesse pela integração entre a agricultura e a pecuária no que diz respeito a técnicas de cultivos que possam ser aplicadas na renovação de pastagens degradadas. Dentre as técnicas pesquisadas, destaca-se a utilização de culturas cultivadas em sistemas de sucessão, rotação ou em consórcios com espécies forrageiras (Kichel et al., 1998; Kluthcouski et al., 2003). A recuperação de pastagens degradadas de Brachiaria spp. com a semeadura direta de soja em sistemas de rotação cultura anual-pastagem constitui uma das formas de integração mais utilizadas (Kluthcouski \& Yokoyama, 2003). Outra técnica de cultivo baseia-se na semeadura de espécies forrageiras consorciadas com culturas anuais de interesse econômico, como o milho, o arroz e o sorgo (Kluthcouski et al., 2003).

No consórcio da forrageira Brachiaria brizantha com milho, vários trabalhos demonstram que a competição e o sombreamento exercidos pelo milho reduziram o crescimento e a produção de forragem de $B$. brizantha até a senescência da cultura, porém com rápido estabelecimento da pastagem após a colheita do milho (Portes et al., 2000; Jakelaitis, 2004). Por sua vez, em experimentos com o consórcio de milho e Brachiaria spp., Cobucci (2001) e Jakelaitis (2004) relatam que a forrageira não afetou o rendimento de milho e que em outros ensaios foi necessário o uso de herbicidas em doses reduzidas como regulador de crescimento da forrageira para, com isso, assegurar a produção econômica de milho.

A utilização de herbicidas no consórcio entre milho e gramineas forrageiras tem sido uma prática recomendada no controle da interferência exercida pela forrageira sobre a cultura e no controle de plantas daninhas (Jakelaitis et al., 2005; Freitas et al., 2005).
Dentre os herbicidas utilizados, têm-se destacado o atrazine e algumas sulfoniluréias, como o nicosulfuron e a mistura pronta de foramsulfuron + iodosulfuron methyl sodium. No entanto, essas sulfoniluréias são consideradas não-seletivas para plântulas do gênero Brachiaria, quando as aplicações são realizadas em pós-emergência precoce nas doses comerciais indicadas para milho; dessa forma, em consórcio, esses herbicidas são usados em baixas doses, aquém da recomendada para o monocultivo de milho (Jakelaitis et al., 2005).

A atividade microbiana no solo constitui importante fator que influencia o comportamento de herbicidas, e a taxa de dissipação dessas moléculas no ambiente é obtida em função da interação existente entre os microrganismos, o substrato e os constituintes do solo (Aislabie \& Lloyd-Jones, 1995). A taxa de evolução de $\mathrm{CO}_{2}$ do solo tem sido utilizada como índice da atividade e da biomassa microbiana do solo. A biomassa microbiana responsável pelo controle de funções essenciais no solo - como a decomposição e o acúmulo de matéria orgânica, ou transformações envolvendo nutrientes minerais ou compostos no solo - tem sido proposta como medida sensivel de distúrbios no solo, principalmente daqueles resultantes da aplicação de substâncias xenobióticas. Pesquisas indicam que herbicidas afetam negativamente a biomassa microbiana (Edwards, 1989; Wardle, 1994; Perschbacher et al., 1997; Kinney et al., 2005; Santos et al., 2005); no entanto, tais estudos ainda são escassos em condições de clima, sistemas de cultivo e solos tropicais.

O objetivo desta pesquisa foi avaliar os efeitos dos herbicidas atrazine + nicosulfuron, aplicados no consórcio entre milho e Brachiaria brizantha, sobre a atividade e biomassa microbiana do solo e a produtividade de ambas as espécies consorciadas. 


\section{MATERIAL E MÉTODOS}

Realizou-se este trabalho em Coimbra-MG, em Argissolo Vermelho-Amarelo câmbico, onde se cultiva milho consorciado com $B$. brizantha há três anos em sistema de semeadura direta. Quinze dias antes da semeadura, fez-se a dessecação química da vegetação com glyphosate $\left(1.440 \mathrm{~g} \mathrm{ha}^{-1}\right)$ e a coleta de solo à profundidade de $0,20 \mathrm{~m}$, cuja análise química constou de pH em água de 5,30; H+Al, Ca e Mg de 4,29; 2,00 e $0,80 \mathrm{cmol}_{\mathrm{c}} \mathrm{dm}^{-3}$, respectivamente; $\mathrm{P}$ de $25,3 \mathrm{mg} \mathrm{dm}^{-3}$; K de $32,3 \mathrm{mg} \mathrm{dm}^{-3}$; matéria orgânica de $3,75 \mathrm{dag} \mathrm{kg}^{-1}$; e granulometria de 44, 11 e $45 \mathrm{dag} \mathrm{kg}^{-1} \mathrm{de}$ areia, silte e argila, respectivamente.

A semeadura das espécies consorciadas foi feita simultaneamente em 13/12/2004, com semeadora-adubadora específica para o sistema de semeadura direta. O milho, DKB455, foi semeado no espaçamento de $1 \mathrm{~m}$ entre fileiras, sendo utilizadas sete sementes por metro linear. A profundidade de semeadura foi de $4 \mathrm{~cm}$, com adubação de plantio de $320 \mathrm{~kg} \mathrm{ha}^{-1}$ da formulação 08-28-16 $\left(\mathrm{N}-\mathrm{P}_{2} \mathrm{O}_{5}-\right.$ $\left.\mathrm{K}_{2} \mathrm{O}\right)$. B. brizantha cv. Vitória-MG5 com $76 \%$ de valor cultural foi semeado a profundidade de $1,5 \mathrm{~cm}$, no espaçamento de $0,5 \mathrm{~m}$ nas entrelinhas do milho, seguindo a recomendação de $3 \mathrm{~kg} \mathrm{ha}^{-1}$ de sementes puras viáveis. A adubação nitrogenada de cobertura foi realizada com uréia aos 25 dias depois da emergência (DAE) do milho, aplicando-se $80 \mathrm{~kg} \mathrm{ha}^{-1}$ de $\mathrm{N}$.

Os tratamentos avaliados em campo foram compostos do consórcio entre o milho e a forrageira $B$. brizantha tratado com os herbicidas atrazine $\left(1.500 \mathrm{~g} \mathrm{ha}^{-1}\right)$ e a mistura deste com nicosulfuron $\left(0,4\right.$ e $32 \mathrm{~g}^{\mathrm{ha}^{-1}}$, respectivamente), aplicados aos 30 DAE do milho. Também foram avaliadas duas testemunhas, representadas pelo consórcio capinado e sem capina, sendo mantido nessas condições durante todo o ciclo de convivência. Foi adotado o delineamento em blocos completos casualizados (DBC), com quatro repetições. Cada unidade experimental teve $60 \mathrm{~m}^{2}$, constituída por seis fileiras de milho de dez metros de comprimento e doze fileiras da forrageira.

Os herbicidas foram aplicados com pulverizador costal pressurizado com $\mathrm{CO}_{2}$, equipado com barra dotadas de pontas de pulverização TT 110.02, que aspergiu $100 \mathrm{~L} \mathrm{ha}^{-1}$ de calda.
A aplicação foi feita de manhã, com solo úmido, velocidade do vento inferior a $5 \mathrm{~km} \mathrm{~h}^{-1}$, umidade relativa do ar e temperatura de $88 \%$ e $26{ }^{\circ} \mathrm{C}$, respectivamente. As plantas daninhas predominantes antes da aplicação eram Brachiaria plantaginea, Digitaria horizontalis e Bidens pilosa.

Para avaliação da atividade microbiana, as amostras de solo foram coletadas aos sete dias após aplicação dos herbicidas (DAA), no início do florescimento e em pré-colheita do milho. A profundidade amostrada foi de 0 a $10 \mathrm{~cm} \mathrm{e}$ a amostragem foi aleatória, retirando-se dez amostras simples com trado, que constituíram uma única amostra composta por parcela. Em seguida, as amostras foram acondicionadas em sacos plásticos e mantidas sob refrigeração durante o transporte e posterior armazenamento no Laboratório de Herbicidas no Solo da Universidade Federal de Viçosa. As amostras, após serem passadas por peneira de $2 \mathrm{~mm}$, secas ao ar e determinado o teor de água, foram pesadas e incubadas em erlenmeyer com teor de água a $80 \%$ da capacidade de campo.

A respiração microbiana foi estimada a partir da quantidade de $\mathrm{CO}_{2}$ evoluído das amostras de solo, o qual foi capturado em frascos com $100 \mathrm{~mL}$ de $\mathrm{NaOH}\left(0,25 \mathrm{~mol} \mathrm{~L}^{-1}\right)$, em sistema contínuo de fluxo de ar isento de $\mathrm{CO}_{2}$ e umidade após sete dias de incubação. Em seguida, proce deu-se à titulação do $\mathrm{NaOH}$ com $\mathrm{HCl}$ $\left(0,25 \mathrm{~mol} \mathrm{~L}^{-1}\right)$, em que o excesso de $\mathrm{NaOH}$ que não reagiu com o $\mathrm{CO}_{2}$ evoluído foi quantificado. Após a avaliação, determinou-se o carbono da biomassa microbiana (CBM) pelo método descrito por Vance et al. (1987), utilizando-se, em lugar do clorofórmio (fumigação), forno de microondas (irradiação) (Islam \& Weil, 1998), e o quociente metabólico $\left(\mathrm{qCO}_{2}\right)$ foi calculado pela relação entre o $\mathrm{CO}_{2}$ acumulado e o CBM.

Para aferição foram coletadas também amostras de solo das testemunhas que não receberam os herbicidas no campo, as quais foram processadas em laboratório (conforme detalhamento anterior) e adicionadas em erlenmeyer, onde receberam os herbicidas (atrazine + nicosulfuron) por meio de pulverização com uma seringa. Atrazine $\left(1.500 \mathrm{~g} \mathrm{ha}^{-1}\right)$ + nicosulfuron $\left(0,2,4,8,16\right.$ e $\left.32 \mathrm{~g} \mathrm{ha}^{-1}\right)$ foram aplicados com base na área coberta por solo no frasco. Nesse caso, também houve uma testemunha sem herbicidas. Os frascos com 
solo foram incubados por 35 dias em sistema contínuo de fluxo de ar, e as avaliações da respiração microbiana foram realizadas em cinco épocas $(7,14,21,28$ e 35 dias após incubação), constituindo um fatorial $7 \times 5$ com quatro repetições, em DBC. Da mesma forma descrita anteriormente, no final do período de incubação realizou-se a determinação do CBM e do $\mathrm{qCO}_{2}$.

As avaliações da massa seca de plantas daninhas e de $B$. brizantha foram feitas em précolheita do milho por meio de duas amostragens de $1 \mathrm{~m}^{2}$ nas parcelas, onde as plantas foram cortadas rente ao solo, separadas por espécies, secas em estufa de ventilação forçada a $70{ }^{\circ} \mathrm{C}$ até obtenção da massa constante e, posteriormente, pesadas. Também foram determinados o estande final e o rendimento de grãos de milho (13\% de umidade), em área útil de $10 \mathrm{~m}^{2}$ nas parcelas.

A respiração microbiana, o $\mathrm{CBM}$ e o $\mathrm{qCO}_{2}$ - avaliados aos 7 DAA dos herbicidas, no início do florescimento e em pré-colheita do milho foram analisados como parcelas subdivididas, em que os tratamentos no campo constituíram as parcelas e as épocas de avaliação as subparcelas, sendo os resultados submetidos à análise de variância (ANOVA) pelo teste $\mathrm{F}$ e as médias comparadas pelo teste de Tukey a 5\% de probabilidade. Para a respiração microbiana resultante da aplicação dos herbicidas, em laboratório, foram ajustadas curvas de regressão para evolução do $\mathrm{CO}_{2}$ acumulado durante o período de 35 dias de incubação, e para o CBM e o $\mathrm{qCO}_{2}$ foram obtidos modelos de regressão em função das doses testadas. Os modelos referentes ao $\mathrm{CO}_{2}$ acumulado nos 35 dias de incubação foram testados quanto à igualdade de parâmetros e identidade de modelos, conforme procedimento descrito por Regazzi (2002). As massas secas de plantas daninhas e de B.brizantha, bem como o estande e o rendimento de milho, foram submetidos à ANOVA e as médias comparadas pelo teste de Tukey a $5 \%$ de probabilidade.

\section{RESULTADOS E DISCUSSÃO}

Não foi observada interação entre os tratamentos utilizados no consórcio entre milho e $B$. brizantha e as avaliações realizadas aos 7 DAA dos herbicidas, no florescimento e em pré-colheita do milho para atividade respiratória dos microrganismos, mensurada pelo desprendimento de $\mathrm{CO}_{2}$ de amostras de solo (Tabela 1). Os valores encontrados para a atividade respiratória situaram-se entre 47 e $57 \mu \mathrm{g} \mathrm{g}^{-1} \mathrm{~d}^{-1}$ de $\mathrm{CO}_{2}$ liberado. Quando as amostras de solo provindas de área não tratada com herbicidas (testemunha de campo) receberam estes em laboratório e foram incubadas

Tabela $1-\mathrm{CO}_{2}$ liberado pela atividade respiratória, carbono da biomassa microbiana (CBM) e quociente metabólico $\left(\mathrm{qCO}_{2}\right)$ em amostras de solo sob milho consorciado com Brachiaria brizantha retiradas de parcelas submetidas a diferentes manejos culturais, em avaliações realizadas aos sete dias após a aplicação dos herbicidas (DAA), no florescimento e em pré-colheita do milho

\begin{tabular}{|l|c|c|c|c|}
\hline \multicolumn{1}{|c|}{ Tratamento } & $\begin{array}{c}\text { Dose } \\
\left(\mathrm{g} \mathrm{ha}^{-1}\right)\end{array}$ & Atividade respiratória & $\mathrm{CBM}^{2 /}$ & $\mathrm{qCO}_{2}{ }^{3 /}$ \\
\hline Atrazine & 1.500 & $56,392 \mathrm{a}$ & 254,574 a & $0,222 \mathrm{a}$ \\
\hline Atrazine + nicosulfuron & $1.500+4$ & $51,715 \mathrm{a}$ & $239,660 \mathrm{a}$ & $0,216 \mathrm{a}$ \\
\hline Atrazine+ nicosulfuron & $1.500+32$ & $47,775 \mathrm{a}$ & $213,496 \mathrm{a}$ & $0,224 \mathrm{a}$ \\
\hline Testemunha capinada & - & $47,925 \mathrm{a}$ & $244,232 \mathrm{a}$ & $0,196 \mathrm{a}$ \\
\hline Testemunha sem capina & - & $56,605 \mathrm{a}$ & $263,803 \mathrm{a}$ & $0,215 \mathrm{a}$ \\
\hline \multicolumn{1}{|c|}{ Época de avaliação } & & Atividade respiratória & $\mathrm{CBM}$ & $\mathrm{qCO}_{2}$ \\
\hline 7 DAA & - & $49,720 \mathrm{a}$ & $151,435 \mathrm{c}$ & $0,328 \mathrm{a}$ \\
\hline Florescimento do milho & - & $50,048 \mathrm{a}$ & $342,877 \mathrm{a}$ & $0,146 \mathrm{c}$ \\
\hline Colheita do milho & - & $56,480 \mathrm{a}$ & $235,148 \mathrm{~b}$ & $0,240 \mathrm{~b}$ \\
\hline \multicolumn{1}{|c|}{ CV (\%) } & & 11,49 & 18,09 & 24,23 \\
\hline
\end{tabular}

Médias seguidas pelas mesmas letras nas colunas são estatisticamente iguais pelo teste de Tukey a $5 \%$ de probabilidade.

${ }^{1 /} \mu \mathrm{g} \mathrm{g}^{-1} \mathrm{~d}^{-1} \mathrm{CO}_{2} ;{ }^{2 /} \mu \mathrm{g} \mathrm{g}^{-1} ; \mathrm{e}^{3 /} \mu \mathrm{g} \mathrm{CO}_{2} \mu \mathrm{gBM}^{-1} \mathrm{~d}^{-1}$. 
por cinco semanas, também não foi verificado efeito das doses crescentes de nicosulfuron associado ao atrazine, do atrazine isolado e do solo não-tratado, sendo a taxa de desprendimento de $\mathrm{CO}_{2}$ explicada por somente um modelo de regressão, em função do período de incubação (Figura 1). Nesse modelo foi observado que $\mathrm{O} \mathrm{CO}_{2}$ acumulado expressouse linearmente em todos os tratamentos, com respiração média de $12,44 \mu \mathrm{g} \mathrm{g}^{-1} \mathrm{~d}^{-1} \mathrm{CO}_{2}$. Assim, verificou-se que, para o Argissolo Vermelho Amarelo, a quantidade de carbono adicionada via nicosulfuron ou atrazine, nas doses testadas, não promoveu alterações na atividade respiratória dos microrganismos.

O CBM também não foi afetado em decorrência do manejo adotado durante a convivência das espécies consorciadas (Tabela 1). Todavia, foram observados maiores valores de CBM no florescimento do milho, seguidos das avaliações realizadas em pré-colheita e aos 7 DAA dos herbicidas. De acordo com Cattelan \& Vidor (1990), a atividade e o CBM são influenciados, entre outros fatores, pela temperatura, umidade, aeração e disponibilidade de substrato no solo. No entanto, nesta pesquisa não foram observadas mudanças climáticas, como déficit hídrico prolongado, que refletissem em alterações significativas no CBM.

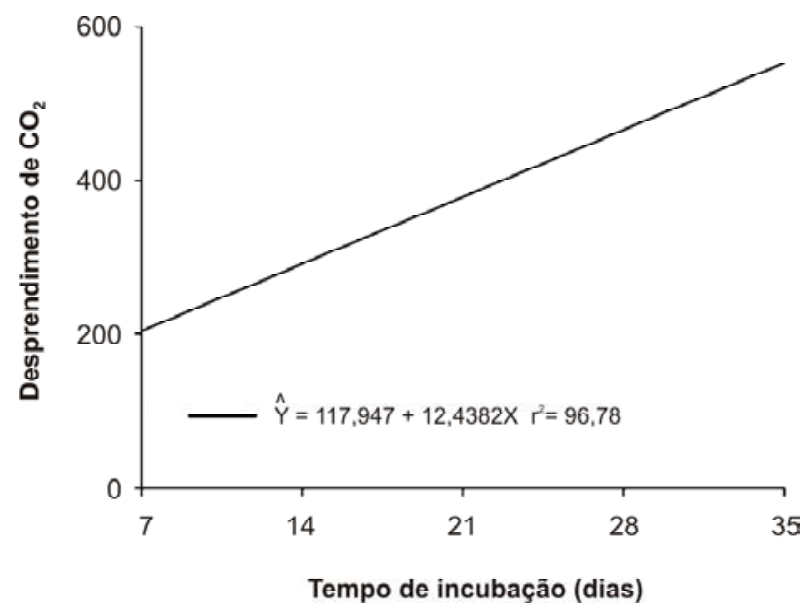

Figura $1-\mathrm{CO}_{2}$ liberado pela atividade microbiana $\left(\mu \mathrm{g} \mathrm{CO}_{2} \mathrm{~g}^{-1}\right.$ de solo) em Argissolo Vermelho-Amarelo câmbico que recebeu os herbicidas atrazine $\left(1.500 \mathrm{~g} \mathrm{ha}^{1}\right)$ em mistura com nicosulfuron $\left(0,2,4,8,16\right.$ e $\left.32 \mathrm{~g} \mathrm{ha}^{-1}\right)$, em laboratório, e a testemunha sem herbicidas incubados por trinta e cinco dias.
Assim, os maiores valores do CBM obtidos no florescimento do milho podem estar associados à maior atividade metabólica da cultura nesta fase, que conseqüentemente aumenta a quantidade de exsudados radiculares e de substrato para microrganismos, podendo ter estimulado a comunidade microbiana por meio do efeito rizosférico. Da mesma forma verificada no florescimento do milho, o maior CBM observado em pré-colheita pode ser em decorrência do crescimento e estabelecimento de $B$. brizantha nessa época, sendo que a forrageira se estabelece a partir da senescência do milho e da entrada de radiação no dossel da cultura (Jakelaitis, 2004).

O CBM também não se alterou quando o solo foi tratado com herbicidas em condições de laboratório (Figura 2). Tratado com a mistura de atrazine e as doses crescentes de nicosulfuron, o CBM médio foi de 332,29 $\mu \mathrm{g} \mathrm{g}^{-1}$ de carbono, enquanto para a testemunha não-tratada ele foi de $363,34 \mu \mathrm{g} \mathrm{g}^{-1}$. Igualmente observado para o $\mathrm{CO}_{2}$, verifica-se que em solo com aporte de matéria orgânica as moléculas herbicidas não se proveram de substrato significativo para a microbiota ou não causaram efeito tóxico sobre esta a ponto de alterar significativamente este indicador da qualidade do solo.

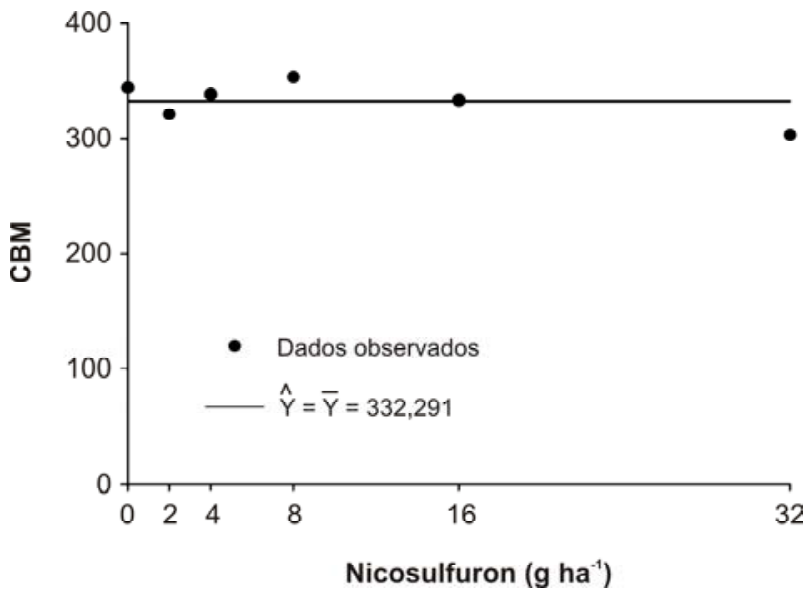

Figura 2 - Carbono da biomassa microbiana (CBM) ( $\mu \mathrm{g} \mathrm{g}^{-1} \mathrm{de}$ solo) em Argissolo Vermelho-Amarelo câmbico que recebeu os herbicidas atrazine em mistura com nicosulfuron $\left(0,2,4,8,16\right.$ e $\left.32 \mathrm{~g} \mathrm{ha}^{-1}\right)$, em laboratório. A CBM da testemunha sem herbicida foi de $363,34 \mu \mathrm{g} \mathrm{g}^{-1}$ de solo.

Planta Daninha, Viçosa-MG, v. 25, n. 1, p. 71-78, 2007 
Outro indicador de qualidade do solo é o quociente metabólico $\left(\mathrm{qCO}_{2}\right)$, proposto por Anderson \& Domsch (1985), o qual prediz que, à medida que a biomassa microbiana se torna eficiente em utilizar os recursos, menor quantidade de carbono é perdida como $\mathrm{CO}_{2}$ pela respiração, sendo este imobilizado no tecido microbiano; conseqüentemente, menor $\mathrm{qCO}_{2}$ representa biomassa microbiana mais estável, ou ambiente com menor grau de distúrbio. Assim, da mesma forma verificada para a atividade respiratória e para o CBM, os tratamentos adotados no manejo da interferência da forrageira com o milho não influenciaram esta variável (Tabela 1). Entretanto, à medida que se avançaram as fases fenológicas das espécies consorciadas e, conseqüentemente, houve aumento do CBM do solo, foram observados menores valores do $\mathrm{qCO}_{2}$, refletindo a maior eficiência dos microrganismos em utilizar os substratos orgânicos disponiveis. Observouse também que o solo incubado e tratado com os herbicidas em laboratório não promoveu alteração significativa do $\mathrm{qCO}_{2}$, provavelmente pelo benefício advindo do conteúdo de carbono orgânico presente nesse solo, que lhe confere maior estabilidade perante substâncias adicionadas ao sistema (Figura 3). A avaliação do $\mathrm{qCO}_{2}$ fornece uma idéia da estabilidade do solo entre sistemas de cultivo (Santos, 2005). Em trabalhos realizados por Santos et al. (2005) com herbicidas e sistemas de cultivo, foi observado que o $\mathrm{qCO}_{2}$ de solos preparados com aração e gradagem foi superior ao observado em semeadura direta, evidenciando menor condição de distúrbio neste último; que, da mesma forma, a aplicação de herbicidas promove aumento no $\mathrm{qCO}_{2}$ em solo sob preparo convencional; e que o efeito negativo de herbicidas sobre a microbiota do solo é diminuído em semeadura direta.

Quanto às plantas daninhas, foi observada maior produção de massa seca nas parcelas não-capinadas e naquelas tratadas somente com o herbicida atrazine, em relação às demais tratadas com nicosulfuron, independentemente da dose testada (Tabela 2). Esse fato deveu-se à eficiência do atrazine no controle de $B$. pilosa e à ineficiência no controle das gramineas $D$. horizontalis e $B$. plantaginea. Acrescentando o nicosulfuron ao atrazine,

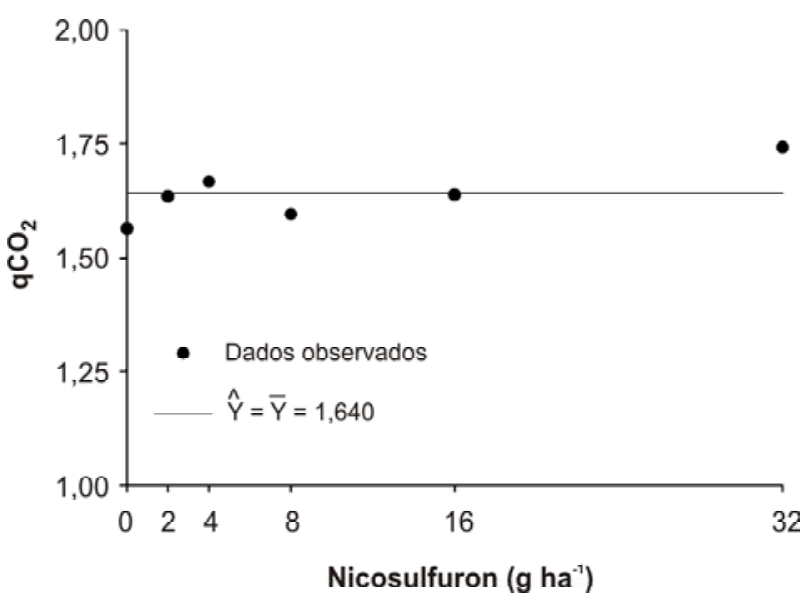

Figura 3 - Quociente metabólico $\left(\mathrm{qCO}_{2}\right)\left(\mu \mathrm{g} \mathrm{CO}_{2} \mu \mathrm{g} \mathrm{CBM}{ }^{-1}\right.$ no período de incubação) em Argissolo Vermelho-Amarelo câmbico que recebeu os herbicidas atrazine em mistura com nicosulfuron $\left(0,2,4,8,16\right.$ e $\left.32 \mathrm{~g} \mathrm{ha}^{-1}\right)$, em laboratório. $\mathrm{O} \mathrm{qCO}_{2}$ da testemunha sem herbicida foi de $1,633 \mu \mathrm{g} \mathrm{CO}_{2} \mu \mathrm{g} \mathrm{CBM}^{-1}$ no período de incubação.

Tabela 2 - Massa seca de Brachiaria brizantha e de plantas daninhas, população e rendimento de grãos de milho avaliados em pré-colheita do milho em consórcio

\begin{tabular}{|l|c|c|c|c|c|}
\hline \multirow{2}{*}{ Tratamento } & \multirow{2}{*}{$\begin{array}{c}\text { Dose } \\
\left(\mathrm{g} \mathrm{ha}^{-1}\right)\end{array}$} & \multicolumn{2}{|c|}{ Massa seca $\left(\mathrm{kg} \mathrm{ha}^{-1}\right)$} & \multicolumn{2}{c|}{ Milho } \\
\cline { 3 - 6 } & & \multicolumn{2}{|c|}{$\begin{array}{c}\text { População } \\
\left(\text { plantas ha }^{-1}\right)\end{array}$} & $\begin{array}{c}\text { Rendimento } \\
\left(\mathrm{kg} \mathrm{ha}^{-1}\right)\end{array}$ \\
\hline Atrazine & 1.500 & $3.132,4 \mathrm{~b}$ & $3.782,4 \mathrm{a}$ & $51.666,7 \mathrm{a}$ & $2.629,8 \mathrm{~b}$ \\
\hline Atrazine + nicosulfuron & $1.500+4$ & $2.490,0 \mathrm{~b}$ & $982,1 \mathrm{~b}$ & $53.518,5 \mathrm{a}$ & $5.954,2 \mathrm{a}$ \\
\hline Atrazine + nicosulfuron & $1.500+32$ & $517,2 \mathrm{c}$ & $520,5 \mathrm{~b}$ & $55.833,3 \mathrm{a}$ & $6.656,4 \mathrm{a}$ \\
\hline Testemunha capinada & - & $8.136,3 \mathrm{a}$ & - & $52.686,7 \mathrm{a}$ & $5.159,9 \mathrm{a}$ \\
\hline Testemunha sem capina & - & $2.749,2 \mathrm{~b}$ & $4.366,4 \mathrm{a}$ & $53.981,5 \mathrm{a}$ & $2.701,3 \mathrm{~b}$ \\
\hline CV (\%) & & 19,85 & 21,07 & 11,30 & 13,16 \\
\hline
\end{tabular}

Médias seguidas pelas mesmas letras nas colunas são estatisticamente iguais pelo teste de Tukey a 5\% de probabilidade. 
verificou-se supressão no acúmulo de massa seca dessas gramíneas, principalmente B. plantaginea, na ordem de 77,5 e $88,1 \%$ para as doses de 4 e $32 \mathrm{~g} \mathrm{ha}^{-1}$ de nicosulfuron, respectivamente, se comparado às parcelas não-capinadas. Resultados semelhantes quanto à eficiência de controle de plantas daninhas promovida pela mistura de atrazine + nicosulfuron no consórcio de milho e $B$. brizantha são relatados por Jakelaitis et al. (2005) e Freitas et al. (2005).

O acúmulo de massa seca de $B$. brizantha avaliada em pré-colheita do milho está indicado na Tabela 2. A produção de forragem foi superior no consórcio capinado, seguido pela produção do tratamento com atrazine e da testemunha sem capina, os quais foram semelhantes entre si e superiores aos demais tratamentos em que o nicosulfuron foi empregado. Ficou evidente que a toxicidade do nicosulfuron sobre a forrageira - advinda com o aumento da dose e a interferência de plantas daninhas - pode comprometer o rendimento forrageiro, corroborando as informações de Silva et al. (2004) e Jakelaitis (2004). Em convivência com as plantas daninhas, observou-se que as monocotiledôneas $B$. plantaginea e $D$. horizontalis são es pécies altamente agressivas a $B$. brizantha consorciada. A redução promovida por elas foi de 66,2 e 61,5\% no rendimento forrageiro de $B$. brizantha da testemunha, sem capina, e quando se utilizou o atrazine, respectivamente, em comparação com o consórcio capinado. Por outro lado, utilizando o nicosulfuron, nas doses de 4 e $32 \mathrm{~g} \mathrm{ha}^{-1}$, associado ao atrazine, verificouse decréscimo no rendimento forrageiro de $B$. brizantha de 69,4 e 93,6\%, respectivamente, comparado à testemunha capinada.

Entretanto, em decorrência de se utilizar o milho como cultura acompanhante à forrageira com o objetivo de ressarcimento dos custos de implantação do pasto, justifica-se o uso da sulfoniluréia em subdoses no controle da interferência da forrageira durante a convivência com a cultura e no controle de plantas daninhas, principalmente quando a área se encontra infestada com monocotiledôneas, como B. plantaginea. Essa justificativa torna-se clara quando se analisa a produção de milho (Tabela 2). A interferência imposta pelas plantas daninhas mostradas na testemunha sem capina e no tratamento com atrazine refletiu em menor produção de grãos: na ordem de $2.458,6 \mathrm{~kg} \mathrm{ha}^{-1}(47,6 \%)$ e $2.530,1 \mathrm{~kg} \mathrm{ha}^{-1}$ (49,0\%) em relação à testemunha capinada e de $3.955,1 \mathrm{~kg} \mathrm{ha}^{-1}(59,4 \%)$ e $4.026,6 \mathrm{~kg} \mathrm{ha}^{-1}$ $(60,5 \%)$ se comparado ao uso da maior dose do nicosulfuron associado ao atrazine (Tabela 2). Já a interferência promovida por $B$. brizantha no milho (testemunha capinada) não diferiu daquela manejada com o nicosulfuron, confirmando que o milho, quando consorciado, apresenta vantagem competitiva em relação a $B$. brizantha, conforme observado por Cobucci (2001), Cobucci \& Portela (2003), Jakelaitis et al. (2005) e Freitas et al. (2005). Os tratamentos avaliados não afetaram a população de plantas de milho (Tabela 2).

Em sintese, verificou-se que a mistura de nicosulfuron + atrazine em subdosagem constitui-se em ferramenta no manejo da interferência e no controle de plantas daninhas no consórcio entre milho e $B$. brizantha, e esta, quando aplicada em agrossistemas estáveis, como o de semeadura direta com aporte de carbono orgânico, não influencia a atividade respiratória dos microrganismos e o CBM e não condiciona o ambiente edáfico à condição de distúrbio ou estresse.

\section{AGRADECIMENTOS}

Ao CNPq, pelo apoio financeiro.

\section{LITERATURA CITADA}

ANDERSON, T. H.; DOMSCH, K. H. Determination of ecophysiological maintenance carbon requirements of soil microorganisms in a dormant state. Biol. Fertil. Soils, v. 1, p. 81-89, 1985 .

AISLAYLABIE, J.; LLOYD-JONES, G. A. A review of bacterial degradation of pesticides. Aust. J. Soil Res., v. 33, n. 6, p. 925-942, 1995.

CATTELAN, A. J.; VIDOR, C. Flutuações na biomassa, atividade e população microbiana do solo, em função de variações ambientais. R. Bras. Ci. Solo, v. 14, p. 133-142, 1990.

COBUCCI, T.; PORTELLA, C. M. O. Manejo de herbicidas no Sistema Santa Fé e na braquiária como fonte de cobertura morta. In: KLUTHCOUSKI, J.; STONE, L. F.; AIDAR, H. (Eds). Integração lavoura-pecuária. Santo Antonio de Goiás: Embrapa-CNPAF, GO, 2003. 569 p. 
COBUCCI, T. Manejo integrado de plantas daninhas em sistema de plantio direto. In: ZAMBOLIN, L. Manejo integrado fitossanidade: cultivo protegido, pivô central e plantio direto. Viçosa, MG: Universidade Federal de Viçosa, 2001. $721 \mathrm{p}$.

EDWARDS, C. A. Impact of herbicides on soil ecosystems. Crit. Rev. Plant Sci., v. 8, p. 221-257, 1989.

FREITAS, F. C. L. et al. A. Formação de pastagem via consórcio de Brachiaria brizantha com milho para silagem no sistema de plantio direto. Planta Daninha, v. 23, n. 1, p. 49-58, 2005.

ISLAM, K. R.; WEIL, R. R. Microwave irradiation of soil for routine measurement of microbial biomass carbon. Biol. Fertil. Soils, v. 27, p. 408-416, 1998.

JAKELAITIS, A. Técnicas para implantação do consórcio milho com Brachiaria spp. 2004. 73 f. Tese (Doutorado em Fitotecnia) - Universidade Federal de Viçosa, Viçosa, MG, 2004

JAKELAITIS, A. et al. Influência de herbicidas e de sistemas de semeadura de Brachiaria brizantha consorciada com milho. Planta Daninha, v. 23, n. 1, p. 59-68, 2005.

KICHEL, A. N.; MIRANDA, C. H. B.; MACEDO, F. C. L. Uso da cultura do milho para recuperação de pastagens degradadas de Brachiaria decumbens. In: REUNIẪO ANUAL DA SOCIEDADE BRASILEIRA DE ZOOTECNIA, 35., 1998, Botucatu. Anais... Viçosa, MG: Sociedade Brasileira de Zootecnia, 1998. p. 40-42.

KINNEY, C. A.; MANDERNACK, K. W.; MOSIER, A. R. Laboratory investigations into the effects of the pesticides mancozeb, chlorothalonil, and prosulfuron on nitrous oxide and nitric oxide production in fertilized soil. Soil Biol. Biochem., v. 37, p. 837-850, 2005.

KLUTHCOUSKI, J.; YOKOYAMA, L. P. Opções de integração lavoura-pecuária. In: KLUTHCOUSKI, J.; STONE, L. F.; AIDAR, H. Integração lavoura-pecuária. Santo Antonio de Goiás: Embrapa-CNPAF, 2003. p. 129-141.
KLUTHCOUSKI, J.; STONE, L. F.; AIDAR, H. Integração lavoura-pecuária. Santo Antonio de Goiás: EmbrapaCNPAF, EMBRAPA, 2003. 569 p.

PERSCHBACHER, P. W. et al. Evaluation of effects of common aerially-applied soybean herbicides and propanil on the plankton communities of aquaculture ponds.

Aquaculture, v. 157, p. 117-122, 1997.

PORTES, T. A. et al. Análise do crescimento de uma cultivar de braquiária em cultivo solteiro e consorciado com cereais. Pesq. Agropec. Bras., v. 35, n. 7, p. 1349-1358, 2000.

REGAZZI, J. A. Teste para verificar a identidade de modelos de regressão e a igualdade de parâmetros no caso de dados de delineamentos experimentais. R. Ceres, v. 46, n. 266, p. 283-409, 1999.

SANTOS, J. B. Atividade microbiana após aplicação de herbicidas utilizados no cultivo do feijoeiro. 2005. $71 \mathrm{f}$. Tese (Doutorado em Fitotecnia) - Universidade Federal de Viçosa, Viçosa, MG, 2005.

SANTOS, J. B. et al. Atividade microbiana do solo após aplicação de herbicidas em sistemas de plantio direto e convencional. Planta Daninha, v. 23, n. 4, p. 683-691, 2005 .

SILVA, A. A.; JAKELAITIS, A.; FERREIRA, L. R. Manejo de plantas daninhas no sistema integrado agriculturapecuária. In: Manejo integrado: integração agriculturapecuária. Viçosa, MG: Suprema, 2004. v. 6. p. 117-169.

VANCE, E. D. et al. An extraction method for measuring soil microbial biomass. Soil Biol. Biochem., v. 19, p. 703-707, 1987.

WARDLE, D. A. Impact of disturbances on detritus foodwebs in agro-ecossystems of contrasting tillage and weed management practices. Adv. Ecol. Res., v. 26, p. 10-17, 1994. 